\title{
Dysbiosis of the microbiota in neurocritically ill patients associated with coma and death: ammonia as a potential missing link
}

\author{
Patrick M. Honore*, Aude Mugisha, Leonel Barreto Gutierrez, Sebastien Redant, Keitiane Kaefer, \\ Andrea Gallerani and David De Bels
}

$\mathrm{Xu}$ et al. conclude that changes in gut microbiota in neurocritically ill patients seem to have an impact on their mortality [1]. We would like to add some comments. The authors described an overgrowth of opportunistic pathogens defined as dysbiosis in patients with neurocritical illness. This study had similar results to other studies regarding the appearance of pathogens and disappearance of commensals [2, 3]. Further, the authors said that dysbiosis of the microbiota in neurocritical patients can be reasonably presumed to increase the risk of infection, undernutrition, and unconsciousness [1]. Here we would like to link dysbiosis and unconsciousness, where increased production of ammonia may play an important role. Indeed, bacteria residing in the human gut produce urease which is beneficial in healthy hosts but pathogenic in hosts with liver disease [4]. Urea produced by the liver is both excreted in urine and transported into the colon, where it is hydrolyzed by bacterial urease into carbon dioxide and ammonia [4]. Circulating ammonia is correlated with brain damage in patients with acute or chronic liver disease resulting in hepatic encephalopathy. In Xu's study, nearly $40 \%$ of the patients had liver disease [1]. It is somewhat unfortunate that blood ammonia was not measured. This would have been of great utility to better interpret the results of their study $[1,4]$.

$\mathrm{Xu}$ also suggested that critical illness could lead to microbial translocation, potentially explaining the association between specific pathogens and mortality [1]. Another valid explanation, knowing that there was an overgrowth of enterobacteriaceae in this study [1], could be the translocation of endotoxin [5]. Indeed, translocation of endotoxin can trigger sepsis, septic shock, and secondary peritonitis [5].

\footnotetext{
* Correspondence: Patrick.Honore@CHU-Brugmann.be

This comment refers to the article available at https://doi.org/10.1186/ s13054-019-2488-4.

ICU Department, Centre Hospitalier Universitaire Brugmann, Place Van Gehuchtenplein 4, 1020 Brussels, Belgium
}

This may have been an important contributing factor in this study, particularly in the $40 \%$ of patients who had liver disease [1] and therefore were less capable of filtering endotoxin $[1,5]$. Measurement of endotoxin levels could be a useful addition in further studies.

\section{Abbreviation \\ ICU: Intensive care unit}

\section{Acknowledgements \\ We thank a lot Dr. Melissa Jackson (native English colleague) for the critical editing of the manuscript.}

\section{Authors' contributions}

$\mathrm{PMH}$ and DDB designed the paper. All authors participated in the drafting and reviewing. All authors read and approved the final version of the manuscript.

\section{Funding}

None.

\section{Availability of data and materials Not applicable.}

Ethics approval and consent to participate Not applicable.

\section{Consent for publication \\ Not applicable.}

\section{Competing interests}

The authors declare that they have no competing interests.

Received: 8 October 2019 Accepted: 28 November 2019

Published online: 11 December 2019

\section{References}

1. Xu R, Tan C, Zhu J, Zeng X, Gao X, Wu Q, Chen Q, et al. Dysbiosis of the intestinal microbiota in neurocritically ill patients and the risk for death. Crit Care. 2019;23(1):195. https://doi.org/10.1186/s13054-019-2488-4.

2. McDonald D, Ackermann G, Khailova L, Baird C, Heyland D, Kozar R, et al. Extreme dysbiosis of the microbiome in critical illness. mSphere. 2016;1(4): e00199-16.

3. Freedberg DE, Zhou MJ, Cohen ME, Annavajhala MK, Khan S, Moscoso DI, et al. Pathogen colonization of the gastrointestinal microbiome at intensive 
care unit admission and risk for subsequent death or infection. Intensive Care Med. 2018;44(8):1203-11.

4. Shen TC, Albenberg L, Bittinger $K$, Chehoud $C$, Chen YY, Judge CA, et al. Engineering the gut microbiota to treat hyperammonemia. J Clin Invest. 2015;125(7):2841-50. https://doi.org/10.1172/JC179214 Epub 2015 Jun 22.

5. lacob S, lacob DG. Infectious threats, the intestinal barrier, and its Trojan horse: dysbiosis. Front Microbiol. 2019;10:1676. https://doi.org/10.3389/ fmicb.2019.01676 eCollection 2019.

\section{Publisher's Note}

Springer Nature remains neutral with regard to jurisdictional claims in published maps and institutional affiliations. 